\title{
Evaluation and conceptual design of triphenylphosphonium bromide-based deep eutectic solvent as novel thermal nanofluid for concentrated solar power
}

\author{
PYARIMOHAN DEHURY, ASHVINI KUMAR UPADHYAY and TAMAL BANERJEE* \\ Indian Institute of Technology, Guwahati 781039, India \\ *Author for correspondence (tamalb@iitg.ac.in)
}

MS received 24 October 2018; accepted 22 February 2019

\begin{abstract}
In a concentrated solar power (CSP) plant, an increase of heat transfer effect of the working fluid is a key deliverable which is usually obtained by enhancing its thermo-physical properties. The current work reports the synthesis of heat transfer fluids (HTF) based on deep eutectic solvents (DESs) consisting of a hydrogen bond donor (HBD), namely, triphenylphosphonium bromide, and a hydrogen bond acceptor (HBA), namely, ethylene glycol. Initially, the thermophysical properties, namely, density, viscosity, thermal conductivity (TC) and specific heat capacity were measured and compared with the conventional solvents. The properties were further enhanced by the dispersion of spherical $\mathrm{Al}_{2} \mathrm{O}_{3}$ nanoparticles in DESs. The alumina nanoparticles were found to have a negligible effect on the physical properties (density and viscosity) of the base fluid, thereby limiting the pressure drop and also the coefficient of friction. For their potential application as thermal fluids for CSP plants, the thermal properties of DESs and nanoparticle dispersed deep eutectic solvents (NDDESs) were measured within a temperature range of $25-60^{\circ} \mathrm{C}$. The $\mathrm{TC}$ of $1 \mathrm{wt} \% \mathrm{Al}_{2} \mathrm{O}_{3}$ with the base fluid was around eight times higher than the base DES. It was found that the TCs of DES and NDDES were higher when compared to the commercial HTF, namely, Therminol VP-1. Eventually, the Aspen plus flowsheet was conceptualized to ascertain the steam generation rate and the overall heat transfer coefficient of these novel solvents. A combination of U-shaped for latent heat and shell and tube heat for sensible heat was employed in the flowsheet. The CSP scheme gave a steam generation rate of $1.7 \mathrm{~kg} \mathrm{~h}^{-1}$ at $180^{\circ} \mathrm{C}$ with a corresponding DES flow rate of $1 \mathrm{~m}^{3} \mathrm{~h}^{-1}$.
\end{abstract}

Keywords. Deep eutectic solvents; heat transfer fluid; Aspen plus; steam properties.

\section{Introduction}

Concentrated solar power (CSP) is a valuable source of renewable energy. The solar energy stored in the form of thermal fluid can be exploited in thermodynamic cycles such as Brayton cycle to generate turbine power from gas turbine engines. The advantage of such a system is that the energy stored during the sun hours can be used at night-time primarily due to the reusability of solar energy. One of the main limitations for such a process is its elevated cost owing to parabolic mirrors or collectors and a need for a large land area. This makes the process economically faring poorly when compared to conventional energy sources. It is for this reason that methodology should be developed for utilizing the stored energy in an effective manner. It implies that the scientific community needs to improve the overall efficiency of these solar plants. One of them is to improve the overall heat transfer coefficient of the fluid which usually carries the sensible heat.

In this scenario heat transfer fluids (HTF) play an important role, particularly in CSP, where the solar collectors absorb the solar radiation and convert it into heat energy. This energy is then transferred as heat through a HTF [1]. This makes the evaluation of the thermodynamic properties such as viscosity, density, thermal conductivity (TC) and specific heat capacity $\left(C_{\mathrm{p}}\right)$ highly desirable $[2,3]$. But the limitations of the presently used HTF in CSP are manifested in its lower storage capacity and thermal stability. This ultimately results in a lower cycle efficiency and higher operating cost. Therefore, it is essential to enhance the working efficiency of HTF for achieving a cost-effective CSP system. To meet these requirements, nanoparticle dispersed deep eutectic solvents (NDDESs) have great potential as an alternative to conventional HTF. NDDESs, a class of nanofluids, can be synthesized by dispersing a small amount of nanoparticles in bare deep eutectic solvents (DESs). This synthesis is of one pot in nature and usually occurs within a few hours of the metathesis reaction.

DESs refer to mixtures of two or more compounds in which hydrogen bond donors (HBDs) and hydrogen bond acceptors (HBAs) combine together to form liquids upon mixing. These have melting points below than that of the individual components [4-6]. DESs are now considered as low-cost green solvents having equivalent characteristics compared to ionic liquids (ILs) which are also green in nature but expensive. 


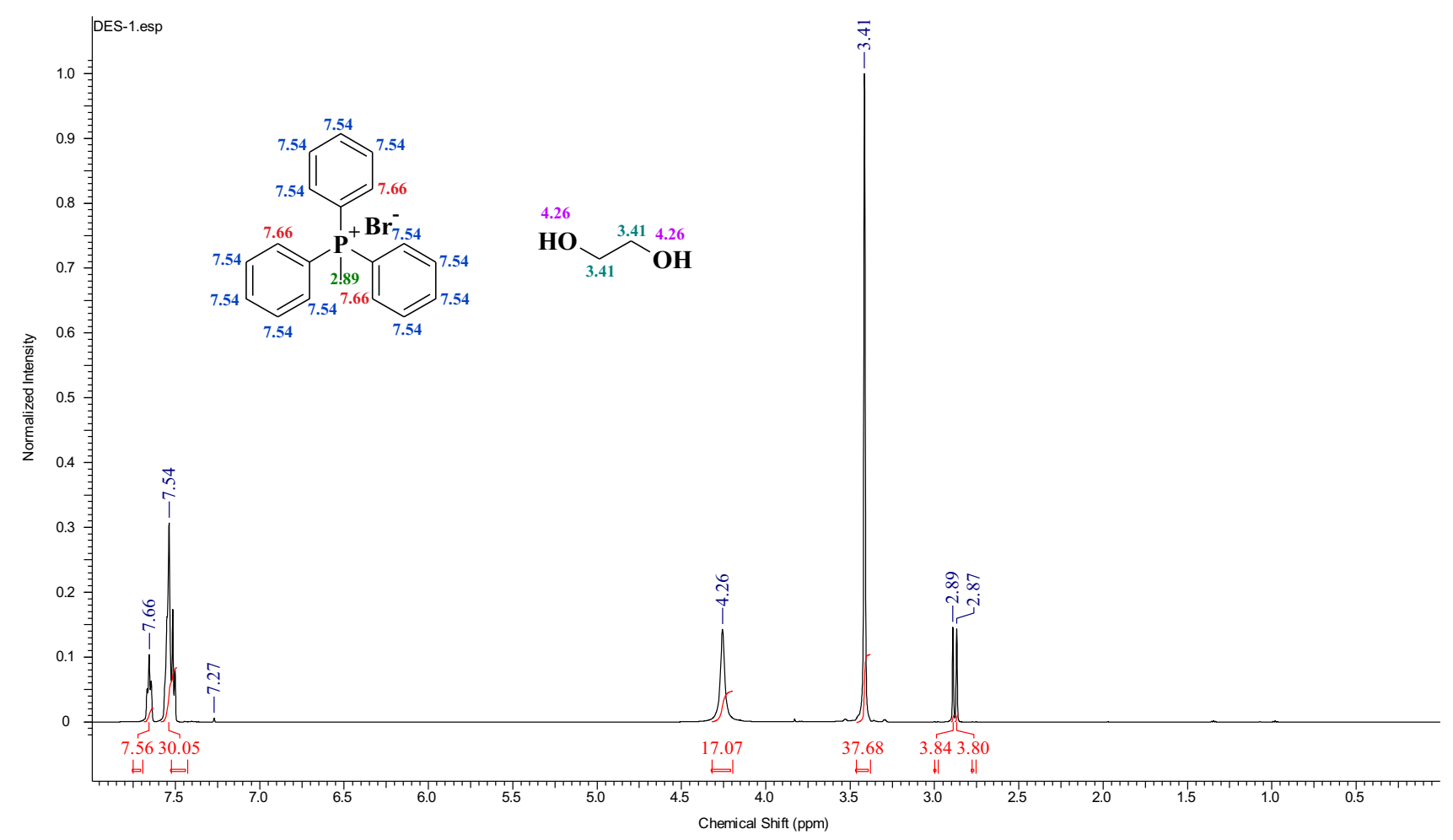

Figure 1. ${ }^{1} \mathrm{H}$ NMR spectra of DES.

Most of the DESs show low volatility, have a wide liquid range, and they are water soluble, non-flammable, non-toxic, biocompatible and biodegradable in nature $[7,8]$. The ensuing sections discuss the physiochemical properties of both the bare fluid (DES) and the nanoparticle-dispersed fluid, NDDES.

\section{Experimental}

\subsection{Chemicals and materials}

Methyltriphenylphosphonium bromide (MTPB) salt having a purity of $98 \%$ was purchased from Sigma Aldrich. Ethylene glycol having a purity of $>99 \%$ was purchased from Merck, Germany. Aluminium oxide $\left(\mathrm{Al}_{2} \mathrm{O}_{3}\right)$ nano-dispersion with a particle size of $50 \mathrm{~nm}$ (TEM) and a surface area $>40 \mathrm{~m}^{2} \mathrm{~g}^{-1}$ (BET) was supplied by Sisco Research Laboratory Pvt. Ltd. All the chemicals were used without further purification. The water content DES was measured by using a Karl Fischer Titrator (870 KF Titrino plus) which was found to be $30,000 \mathrm{ppm}(3 \%)$.

\subsection{Synthesis of DESs}

One mole of MTPB salt, i.e. HBD and four moles of ethylene glycol, i.e. HBAs were added to a flat-bottom flask. This was fitted with a reflux condenser and then kept for 24-48 $\mathrm{h}$ at $60^{\circ} \mathrm{C}$ with stirring until a clear liquid was formed. Then, the DES was maintained at room temperature $\left(25^{\circ} \mathrm{C}\right)$ overnight for equilibrium. To confirm the composition of the DES, ${ }^{1} \mathrm{H}$ nuclear magnetic resonance (NMR) (figure 1) and ${ }^{13} \mathrm{C}$ NMR (figure 2) spectra were recorded to confirm the molar ratio and confirm the absence of any reaction. Furthermore, heteronuclear single quantum coherence (HSQC) two-dimensional (2D)-NMR (figure 3) spectroscopy was performed to confirm the equivalence of carbon and hydrogen atoms formed within the molecule. The ${ }^{1} \mathrm{H}-\mathrm{NMR}$ spectrum of DES consists of the following peaks: ${ }^{1} \mathrm{H}$ NMR $\left(600 \mathrm{MHz}, \mathrm{CDCl}_{3}\right)$ $\delta \mathrm{H} 7.66(1 \mathrm{H}, \mathrm{m}), 7.54(1 \mathrm{H}, \mathrm{m}), 4.26(8 \mathrm{H}, \mathrm{m}), 3.41(16 \mathrm{H}, \mathrm{m})$ and $2.89(3 \mathrm{H}, \mathrm{d})$. The ${ }^{13} \mathrm{C}$ NMR results (ppm) include: ${ }^{13} \mathrm{C}$ NMR (600 MHz, DMSO-d6) $\delta$ C9.82, 63.25, 118.36, 118.95, $130.19,130.27,132.77,132.84$ and 134.99. After the synthesis of DES, NDDES was prepared by mixing $1 \%$ (by wt.) aluminium oxide $\left(\mathrm{Al}_{2} \mathrm{O}_{3}\right)$ nanoparticles with DES. $\mathrm{Al}_{2} \mathrm{O}_{3}$ nanoparticles were dispersed in DES using a vortex and then agitated for $\sim 2 \mathrm{~h}$ to break any possible agglomerated nanoparticles.

\subsection{Density and viscosity}

The densities of DES and NDDES were measured using an Anton Paar densitometer (DMA $4500 \mathrm{M}$ ) in the temperature range of $20-60^{\circ} \mathrm{C}$. As expected, the densities of DES and NDDES were found to decrease with an increase in temperature (figure 4). This is due to the fact that the 


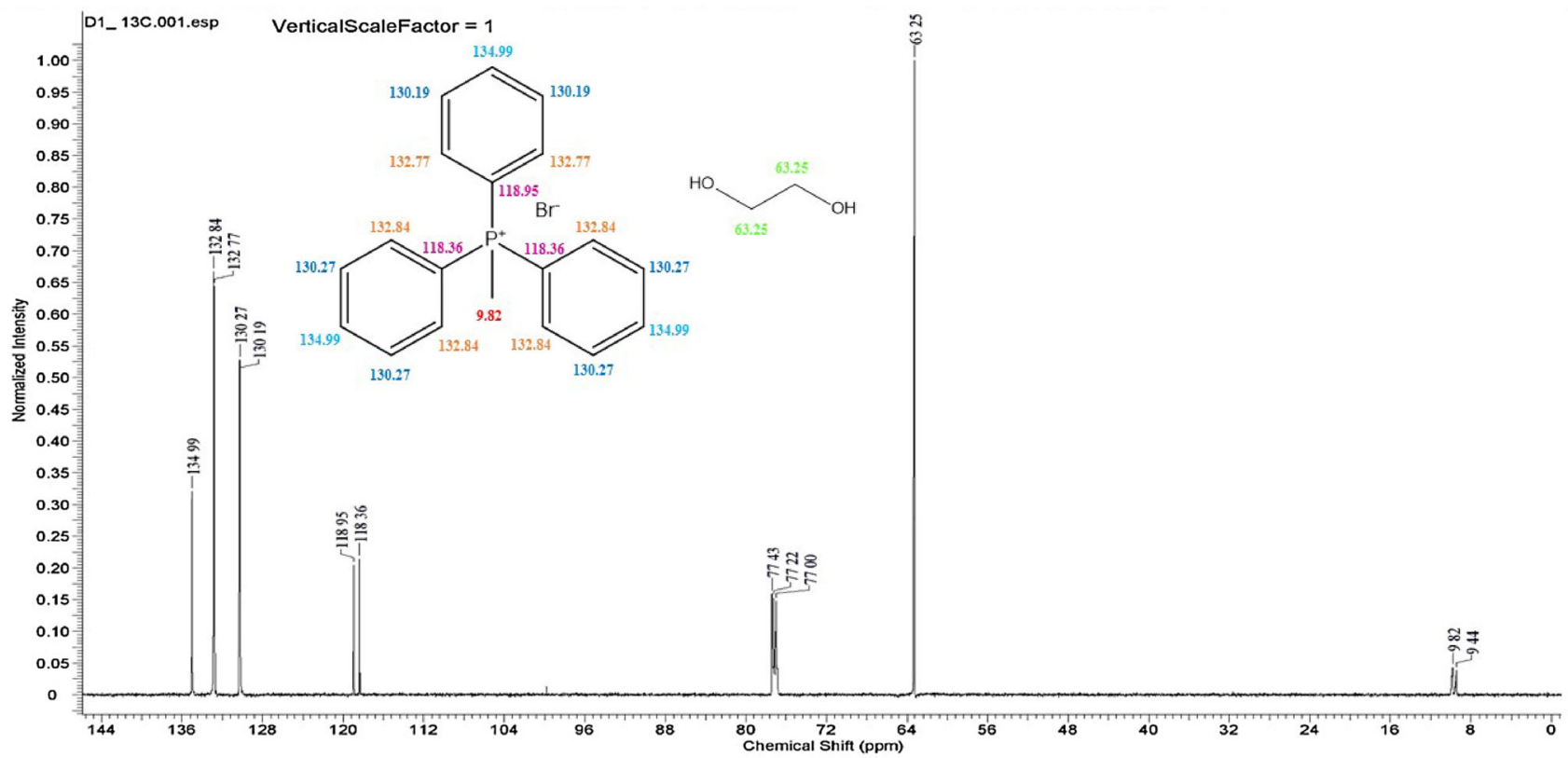

Figure 2. ${ }^{13} \mathrm{C}$ NMR spectra of DES.

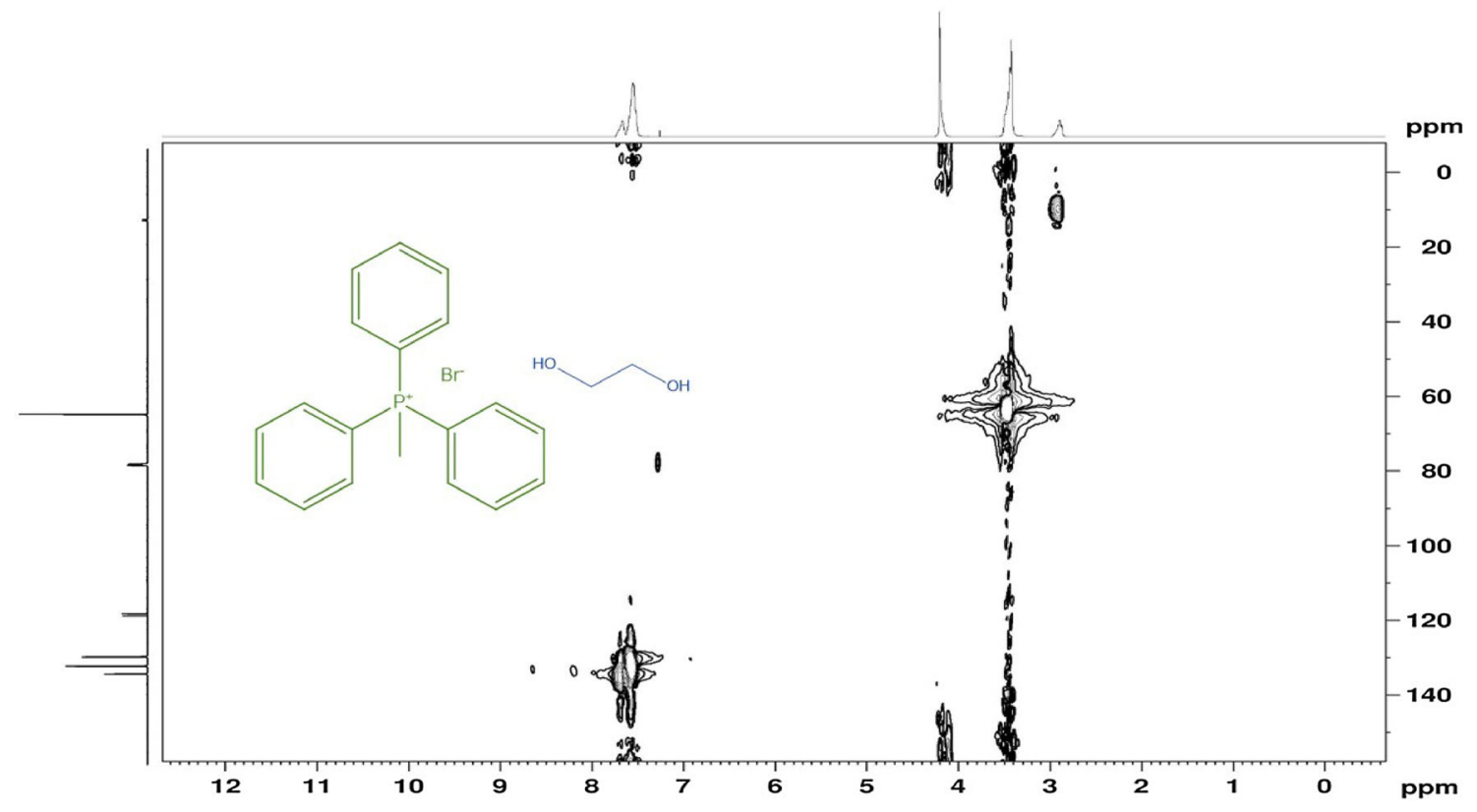

Figure 3. HSQC 2D-NMR spectra of DES.

thermal expansion generally results in a lower density with an increase in temperature. It was found that the experimentally measured densities of NDDES with respect to temperature are significantly lower as compared to base DES. This is one of the required and necessary properties of HTF. However, the densities were higher by $10 \%$, when compared with the commercial solvents, namely, VP-I (diphenyl oxide and biphenyl) [9] and Dowtherm-A (biphenyl and diphenyl oxide) [10].
The viscosities of DES and NDDES were measured using an Anton Paar interfacial rheometer (Physica MCR301) as a function of temperature in the range of $20-60^{\circ} \mathrm{C}$ (figure 5). The viscosity of the DES dramatically decreased from 94.2 to $8.73 \mathrm{cP}$ with an increase in temperature. A similar decrease is seen from 74.1 to $8.15 \mathrm{cP}$ in the case of DES having $1 \% \mathrm{Al}_{2} \mathrm{O}_{3}$ nanoparticles. It confirms that the viscosity of the NDDES is lower than that of DES at the same temperature. This confirms that the addition of nanoparticles decreases the viscosity of the 


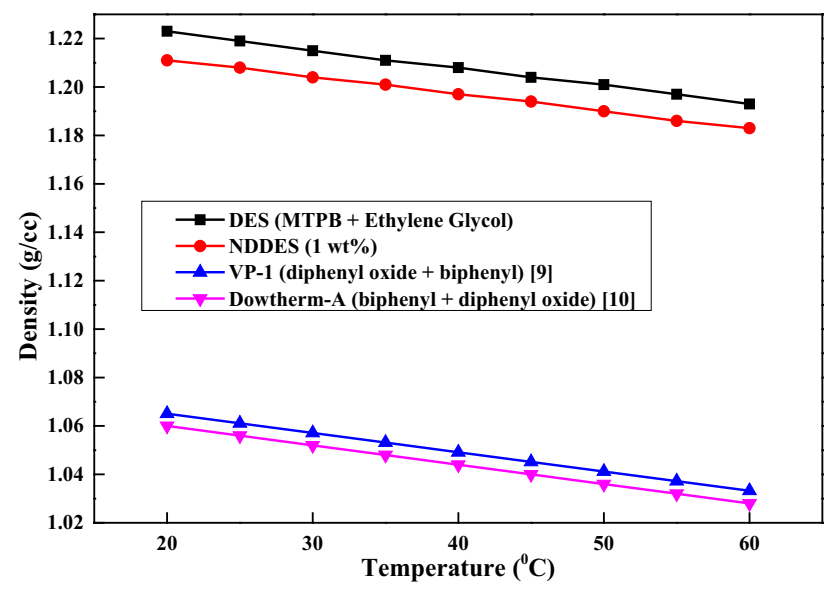

Figure 4. Density variation with the temperature of DES, NDDES, VP-1 and Dowtherm-A.

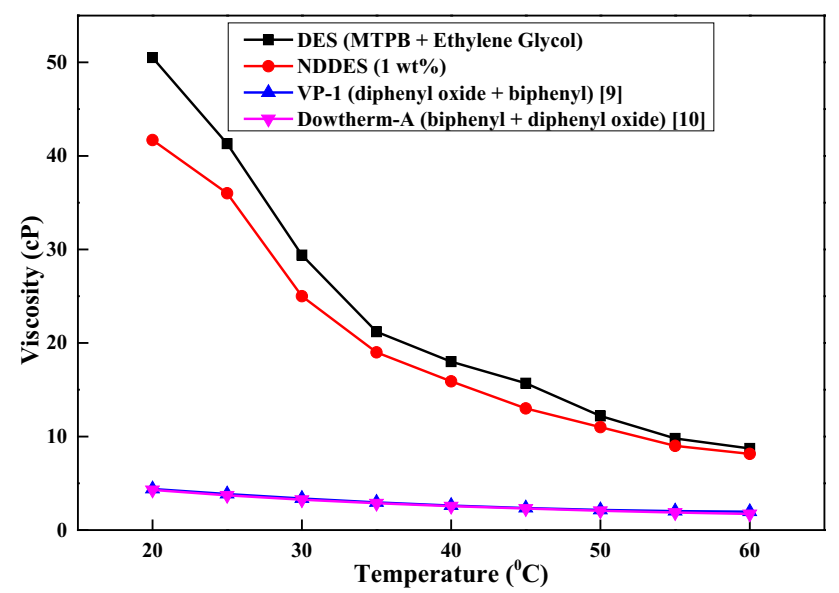

Figure 5. Viscosity variation with temperature of DES, NDDES, VP-1 and Dowtherm-A.

base DES. This is a useful property as it will reduce the flow resistance of the HTF even though its viscosities are higher than that of the commercial ones.

Earlier results have pointed out to the fact that the TC of the ionic liquid-based HTF increases as the diameter of the nanoparticles is reduced. However, the major drawback of the nanofluid is that the coefficient of friction and pressure drop also increases with volume fraction. Thus, an optimum volume or mass fraction of nanoparticles with DES needs to be chosen based on both thermophysical properties and the flow regime. As per an earlier work by Xuan et al [11], the local heat transfer coefficient increases by $60 \%$ for a $\mathrm{Cu}$-water-based nanofluid containing $2 \% \mathrm{Cu}$ nanoparticles by volume, while, on the other hand, the nanofluids possess only an effective TC of $12.5 \%$ higher than that of the base liquid. This may be due to the particle migration which results in a non-uniform distribution of TC and viscosity fields which ultimately reduces the thermal boundary layer thickness.
Overall, the results clearly show that the use of nanofluids significantly improves the convective heat transfer. However, an increase in Reynolds number or volume fraction of particles also results in an increase in heat transfer and pressure drop. For example, in the case of the water- $\mathrm{TiO}_{2}$ nanoparticles, the heat transfer rate of the nanofluid with a concentration of 0.002 was higher than that of the base fluid, while both of them had the same pressure drop in the low Reynolds numbers. Therefore, dilute nanofluid with $1 \mathrm{wt} \%$ is recommended and adopted in this word with DES. Hence, in our studies, NDDES has been explored using spherical $\mathrm{Al}_{2} \mathrm{O}_{3}$ nanoparticles with a size of $70 \mathrm{~nm}$. Additionally, the nanoparticles have proved to have a negligible effect on the physical properties (density and viscosity) of the base fluid, thereby limiting the pressure drop and also the coefficient of friction. We now focus on the remaining two important properties, namely, heat conductivity and capacity which may finally confirm their use as HTF.

\subsection{TC and heat capacity}

The TCs of the base DES and NDDES were measured using a KD2 Pro thermal property analyser (Decagon Device, USA). The principle of measurement is based on the hot wire method. The device has a probe, namely, 'KS-1' having dimensions of $60 \mathrm{~mm}$ length and $1.3 \mathrm{~mm}$ diameter which is inserted vertically into the test sample. For controlling and conducting the measurements, the probe is connected to a microcontroller. The metre was calibrated with standard glycerin. A thermal bath was used to maintain constant temperature for the measuring sample. For better results, the measurement was performed at an interval of $15 \mathrm{~min}$. The temperature accuracy of the bath was within $\pm 0.03^{\circ} \mathrm{C}$. The experiment was performed within a temperature range of $20-60^{\circ} \mathrm{C}$. The TC of $1 \% \mathrm{Al}_{2} \mathrm{O}_{3}$ nanoparticles or NDDES when compared to DES indicated an increase in $8 \%$ (figure 6) across the temperature range. Both the NDDES and DES here show a TC which is almost $70 \%$ more than that of the commercial HTF. However, the increase is more pronounced at a lower temperature.

In a similar manner, the heat capacity of DES and NDDES was evaluated with a differential scanning calorimeter (DSC1, Mettler Toledo, Germany) by the sapphire method. The heat capacity of DES varied from 3.69 to $4.67 \mathrm{~J} \mathrm{~g} \mathrm{~g}^{-1}{ }^{\circ} \mathrm{C}^{-1}$ as the temperature was increased from 20 to $60^{\circ} \mathrm{C}$. The corresponding values of NDDES were from 3.98 to $5.04 \mathrm{~J} \mathrm{~g}^{-1}{ }^{\circ} \mathrm{C}^{-1}$ (figure 7). This indicated that the heat capacity of the DES and NDDES was found to increase within the experimental temperature range. The values were almost three times of the reported commercial HTFs. Thus, high TC and heat capacity values can offset the denser and viscous NDDES as potential HTFs. However, it should be noted that the commercial solvents are well established up to temperatures as high as $400^{\circ} \mathrm{C}[9,10]$. Our study at this stage merely points out to the application of these low-cost NDDES for moderate temperatures so as to avoid the crystal formation which is known for Therminol VP-1 [9]. We shall now attempt to study its 


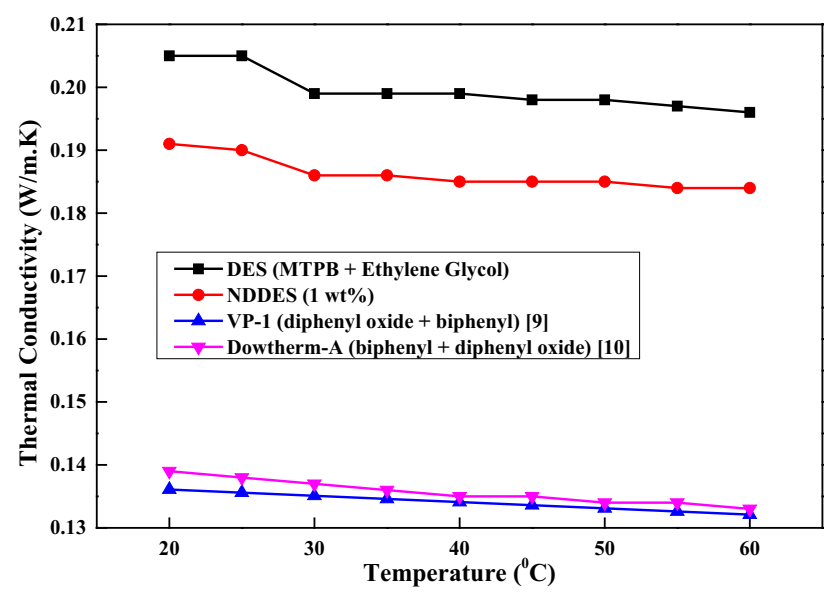

Figure 6. TC of DES, NDDES, VP-1 and Dowtherm-A as a function of temperature.

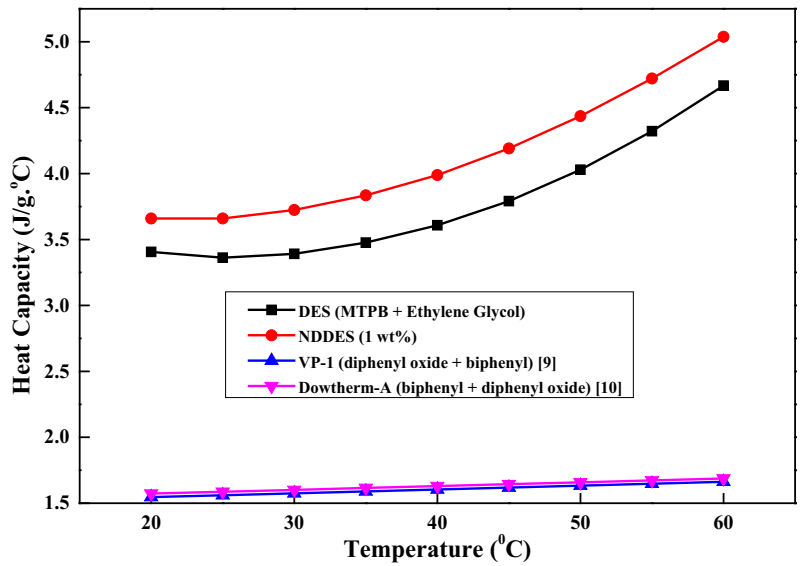

Figure 7. Specific heat capacity of DES, NDDES, VP-1 and Dowtherm-A as a function of temperature.

performance in a two-stage heat exchanger for an evaluation of its steam power.

\section{Conceptual design for the estimation of steam property}

\subsection{Aspen plus flowsheet}

The Aspen flowsheet of the steam generation system given below (figure 8) is a pictorial depiction of the simulation which was performed using DES as the pseudocomponent. It may be noted that the DES compound containing a HBD and HBA is not available within the Aspen plus database.

In this case, the Cosmo-Sac model [12,13] within the Aspen module has been invoked. Initially, the sigma profiles of both HBD and HBA were obtained and then added to get a sigma profile of complete DES. The methodology, equations and theory behind Cosmo-based models are available elsewhere and in our previous work $[12,13]$. Here, we study only DES, as the incorporation of nanoparticles within Aspen is beyond the scope of the current work.

In the flowsheet, two heat exchangers, namely, the Ushaped (U-S) heat exchanger and the shell and tube (S-T) heat exchanger are connected in series and operated in a countercurrent manner with an optimum specification as shown in figure 8. While the U-tube refers to the latent heat, the shell and tube refer to sensible heat exchange. DES-IN has been used as the shell side hot fluid in the $\mathrm{S}$-T heat exchanger, while DES-MID was as an outlet, which is treated as an input for the U-S heat exchanger on the shell side. WTR-IN is the water flow rate in the tube side of the U-S heat exchanger as cold fluid, while WTR-OUT is the input for the S-T heat exchanger and STEAMOUT is measured as a mixture of vapour and liquid where the steam and the liquid part of water are separated.

\subsection{Calculation model}

In the Aspen simulation, heat duty and heat transfer coefficient of the U-S heat exchanger and the S-T heat exchanger have been investigated. Heat released by DES is given as:

$$
Q_{\text {rel }}=q_{\mathrm{v}, \mathrm{DES}} \rho c_{\mathrm{p}}\left(T_{\mathrm{in}}-T_{\text {out }}\right),
$$

where $q_{\mathrm{v}, \mathrm{DES}}$ is the volumetric flow rate of DES, $\rho$ is the density of DES, $c_{\mathrm{p}}$ is the specific heat capacity of DES and $T_{\text {in }}$ and $T_{\text {out }}$ are the inlet and outlet temperatures of DES. The total heat absorbed by water/steam in the whole system is given by:

$$
Q_{\mathrm{ab}}=q_{\mathrm{m}, \mathrm{w}}\left(h_{\text {out }}-h_{\mathrm{in}}\right),
$$

where $q_{\mathrm{m}, \mathrm{w}}$ is the mass flow rate of water/steam and $h_{\text {out }}$ and $h_{\text {in }}$ are the enthalpies of outlet and inlet water/steam obtained from the Aspen simulation. The heat flux of the steam generation system is:

$$
q=\frac{Q_{\mathrm{ab}}}{S_{\mathrm{total}}}
$$

where $S_{\text {total }}$ is the total heat transfer area of the steam generation system. The logarithmic mean temperature difference (LMTD) of the system is estimated as:

$$
\Delta T_{\mathrm{m}}=\frac{\Delta T_{\text {in }}-\Delta T_{\text {out }}}{\ln \left(\Delta T_{\text {in }} / \Delta T_{\text {out }}\right)},
$$

where $\Delta T_{\text {in }}$ and $\Delta T_{\text {out }}$ are the temperature difference at the end of the steam generation system. The overall heat transfer coefficient of the system is calculated as:

$$
U=\frac{q}{\Delta T_{\mathrm{m}}}
$$




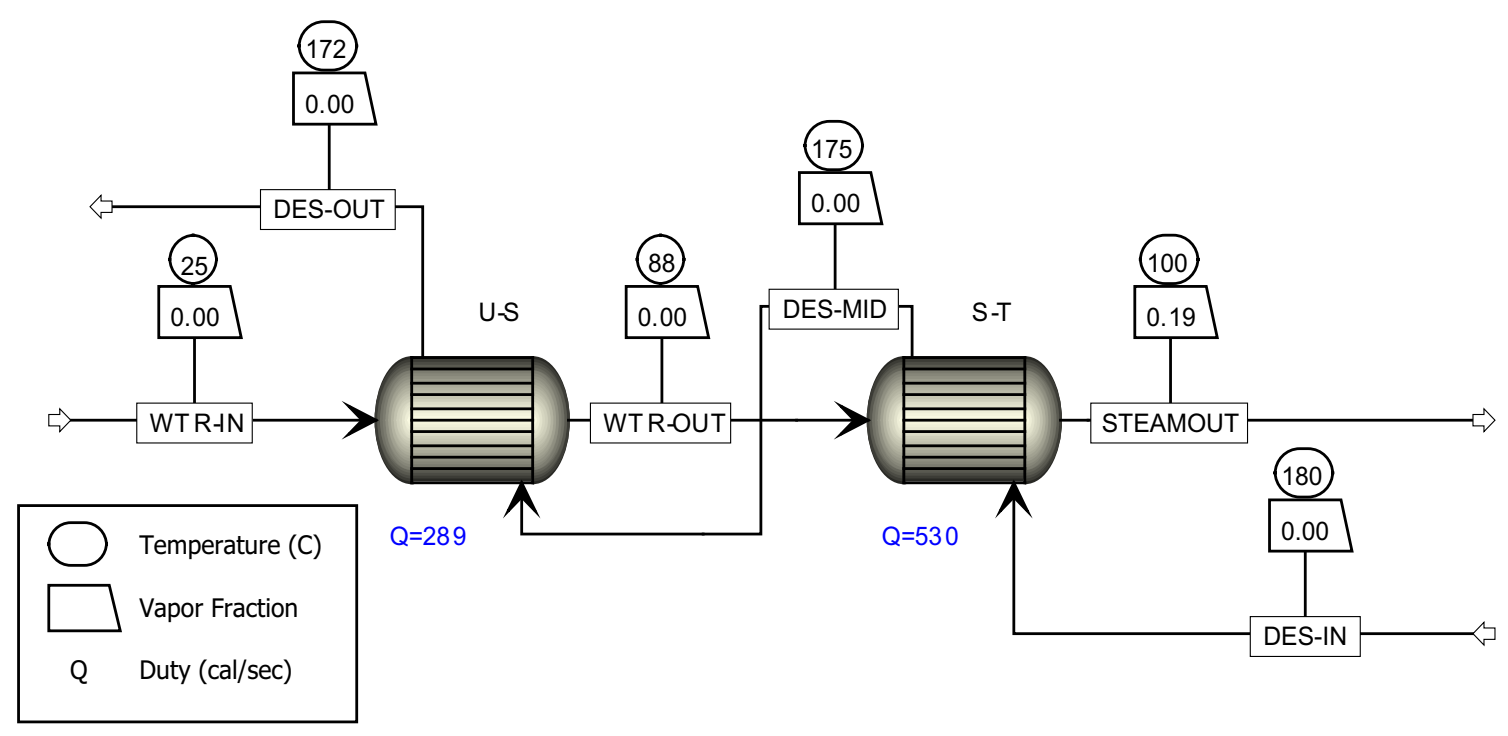

Figure 8. Aspen plus flowsheet for a steam generation system using DES.

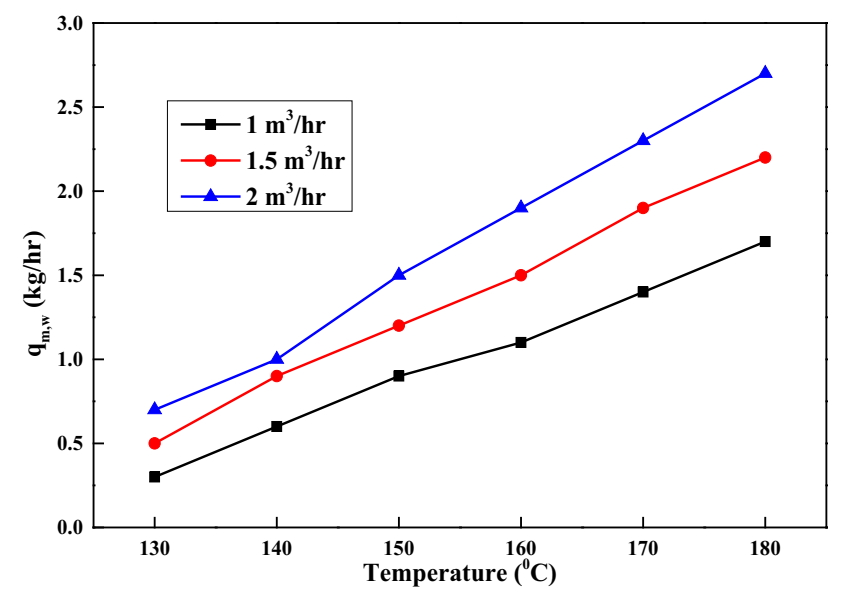

Figure 9. Steam generation rate with the DES flow rate as a function of temperature.

Substituting the value of $q$ and $Q_{\mathrm{ab}}$ from equations (2 and 6), respectively, in equation (3), we obtain:

$$
U \Delta T_{\mathrm{m}}=\frac{q_{\mathrm{m}, \mathrm{w}}\left(h_{\mathrm{out}}-h_{\mathrm{in}}\right)}{S_{\text {total }}} .
$$

We shall now observe the effect of the steam generation rate based on the temperature, heat exchange duty and DES flow rate.

\subsection{Effect of the DES flow rate}

In figure 9, the vapour generation rate is found to increase with both temperature and the DES flow rate. Increasing the flow rate of DES reduces the residence time of the fluid but simultaneously increases the Reynolds number on the shell side pass.

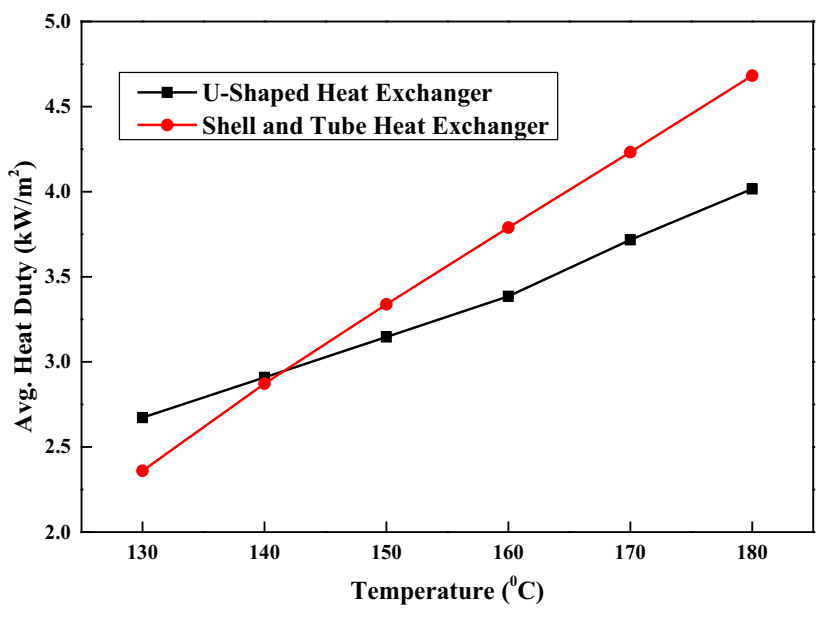

Figure 10. Average heat duty for the shell and tube and U-shaped heat exchanger as a function of temperature at a flow rate of $1 \mathrm{~m}^{3} \mathrm{~h}^{-1}$.

This increased Reynolds number shall increase the overall heat transfer coefficient which results in a higher vapour generation rate as well as increasing the temperature of DES. It eventually increases the LMTD. On increasing the DES flow rate as well as the temperature, the gap between the vapour generation rates is increasing, implying that the overall heat transfer coefficient and LMTD increase with both the flow rate of DES and the temperature.

\subsection{Average heat duty for shell tube and U-shaped heat exchanger}

In this case, the simulation result (figure 10) has been plotted in the temperature range of $130-180^{\circ} \mathrm{C}$ and a flow rate 


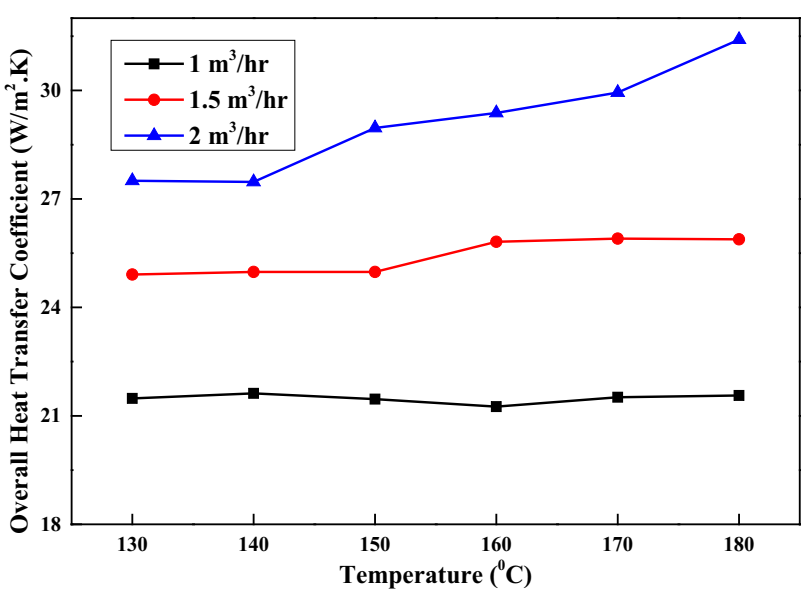

Figure 11. Overall heat transfer coefficient of the steam generation system as a function of temperature.

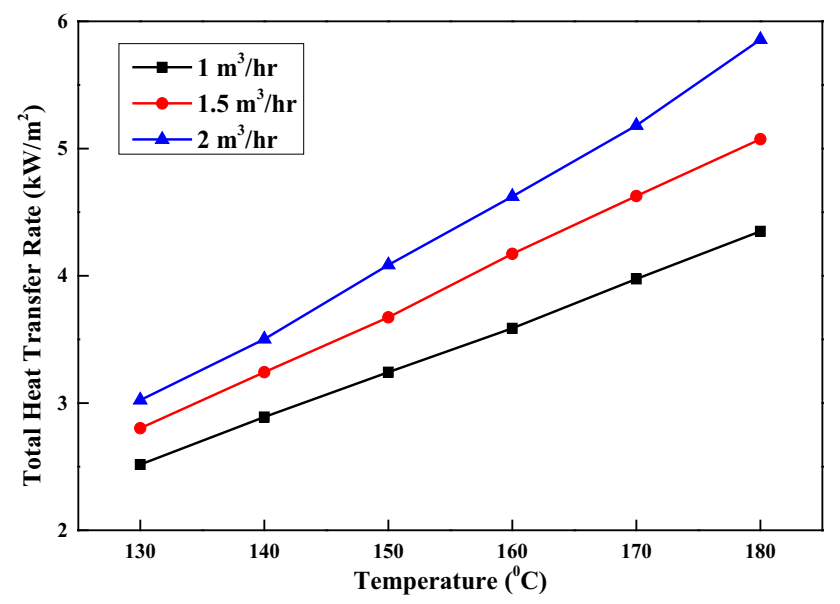

Figure 12. Total heat transfer rate of the steam generation system as a function of temperature.

of $1 \mathrm{~m}^{3} \mathrm{~h}^{-1}$ of DES. With rising DES inlet temperature, the average heat duty increases for both the shell and tube and U-shaped heat exchanger. The average heat duty slope is higher for the shell and tube heat exchanger because the primary DES input flow rate is given for the shell and tube heat exchanger with the highest temperature in the system. This causes higher LMTD and a higher overall heat transfer coefficient, resulting in a higher heat transfer rate.

\subsection{Effect of the overall heat transfer coefficient and total heat duty}

In figure 11, the overall heat transfer coefficient is plotted in the temperature range of $130-180^{\circ} \mathrm{C}$ for three different flow rates of DES. In general, the overall heat transfer coefficient does not vary at low Reynolds number because of its low interaction of particles causing a lower heat transfer

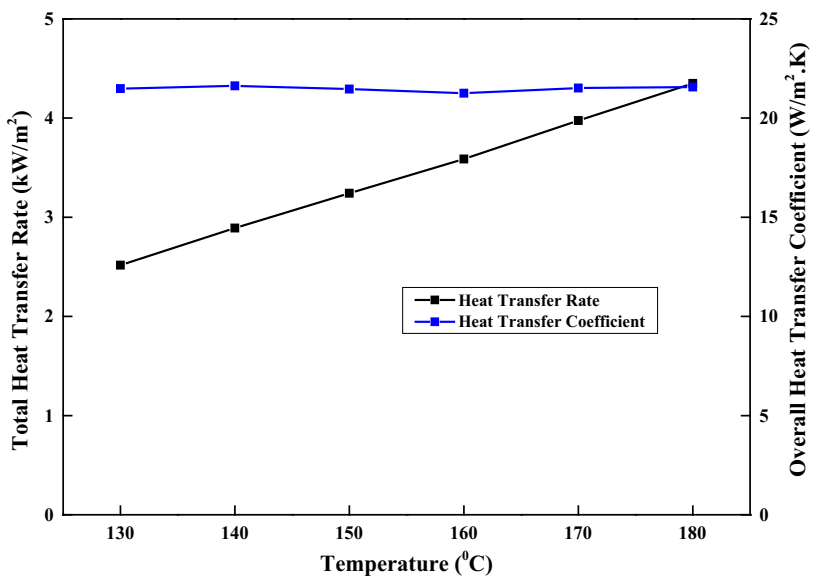

Figure 13. Total heat transfer rate and overall heat transfer coefficient within a temperature range of $130-180^{\circ} \mathrm{C}$.

rate between the particles. However, the overall heat transfer coefficient tends to increase because of the high heat transfer rate between the DES particles even at low Reynolds number with a very low change in the DES flow rate.

In figure 12 , the total heat transfer rate is plotted in the temperature range of $130-180^{\circ} \mathrm{C}$ for three different flow rates of DES. The total heat transfer rate was found to increase with the inlet DES temperature and the flow rate. Considering a single DES flow rate, the total heat transfer rate increases with an increase in the difference between wall temperature and bulk temperature. Similarly, for a particular temperature, the total heat transfer rate again increases which is due to the previous observation as shown in figure 10. The difference between the total heat transfer rates is found to increase with the temperature and LMTD.

In figure 13, the total heat transfer rate and the overall heat transfer coefficient are plotted in the temperature range of $130-180^{\circ} \mathrm{C}$ and $1 \mathrm{~m}^{3} \mathrm{~h}^{-1}$. The overall heat transfer coefficient for all the flow rates of DES is constant within the range of $130-180^{\circ} \mathrm{C}$. It can be concluded that the total heat transfer rate increases with an inlet temperature of DES and the flow rate of DES but the overall heat transfer coefficients are constant with inlet DES temperature.

\section{Conclusion}

In this study, the TC and heat capacity of the newly synthesized DES and NDDES are reported. NDDES is a one-pot synthesis of a salt, a $\mathrm{HBD}$ and $1 \% \mathrm{Al}_{2} \mathrm{O}_{3}$. The results show that the TC and heat capacity are enhanced significantly when compared with the commercial HTFs. These preliminary results indicate that NDDES may be a potential HTF in solar collectors. The Aspen Plus simulation point out to the fact that the steam generation rate increases with both the temperature and the flow rate of DES. The average heat transfer coefficient of the shell and tube heat exchanger 
was found to be higher than the U-shaped heat exchanger at a higher temperature. This eventually maximizes the steam generation rate, which implies that the DES can be used for enhancing the heat transfer coefficient in CSP plants.

\section{Acknowledgements}

This study was financially supported by a research grant from the IMPRINT INDIA (Proposal No. 4077), Ministry of Human Resource Development (MHRD), Government of India.

\section{References}

[1] Bosatra M, Fazi F, Lionetto P F and Travagnin L 2010 Proc. Power-Gen. Europe Amsterdam, The Netherlands, June 8-10

[2] Abel M S, Siddheshwar P G and Mahesha N 2009 Int. J. NonLinear Mech. 441
[3] Abu-Nada E 2009 Int. J. Heat Fluid Flow 30679

[4] Welton T 1999 Chem. Rev. 992071

[5] Wasserscheid P and Keim W 2000 Angew. Chem. Int. Ed. 39 3772

[6] Abbott A P, Capper G, Davies D L, Munro H L, Rasheed R K and Tambyrajah V 2001 Chem. Commun. 20012010

[7] Singh B S, Lobo H R and Shankarling G S 2012 Catal. Commun. 2470

[8] Jhong H R, Wong D S H, Wan C C, Wang Y Y and Wei T C 2009 Electrochem. Commun. 11209

[9] Eastman Company, USA Available: https://www.therminol. com/products/Therminol-VP1 (accessed 15th September 2015)

[10] Dow Chemicals, USA Available: http://www.dow.com/ heattrans/products/synthetic/dowtherm.htm (accessed 25th September 2015)

[11] Xuan Y and Wang J 2003 J. Heat Transf. 125151

[12] Banerjee T, Bharti A, Kundu D and Rabari D 2017 Phase equilibria in ionic liquid facilitated liquid-liquid extractions (Boca Raton, London, New York: CRC Press) 1st edn

[13] Bharti A, Verma R, Prerna B, Namdeo S, Malviya A, Banerjee T et al 2018 Fluid Ph. Equilibria 46273 